

\section{O HABITAT CAIPIRA E O CULTIVO DO MILHO NO ALTO VALE DO PARAÍBA}

\section{Jane Victal Ferreira}

Arquiteta e Doutora pela Universidade de São Paulo (USP) e Professora do Programa de Pós-Graduação em Urbanismo Puc-Campinas (POSURB).

\section{Adelita Araujo de Souza}

Advogada e arquiteta. Mestre em Urbanismo, atualmente aluna do Programa de Doutorado em Urbanismo da Puc-Campinas e Doutorado Sanduíche no Programa de Urbanismo e Ordenação do Território da Universidade Politécnica da Catalunha

\section{RESUMO}

A paisagem natural do Alto Vale do Paraíba é composta de pequenos morros, rios, ribeirões e fragmentos remanescentes de mata atlântica, que no passado cobriu todo o seu território. No período do ciclo do ouro, os caminhos induziram a formação de cidades atualmente preservadas como patrimônio material do Brasil colonial. Com o declínio do ciclo do ouro, essas cidades passaram a nuclear uma cultura de subsistência que ocorria nos seus arredores e no interior das matas. Essa cultura, chamada de Caipira, tem suas origens na miscigenação entre portugueses e índios, que a partir do plantio das roças de milho desenvolveram seus utensílios, técnicas, tradições, arquitetura, organização espacial e, sobretudo uma estreita ligação com os elementos naturais do Alto Vale do Paraíba. 
ID_PESQUISAS

\section{RESUMEN}

El paisaje natural de Alto Valle do Paraíba, en el sureste de Brasil se compone de pequeñas colinas, ríos, arroyos y algunos fragmentos que quedan de bosque atlántico, que una vez cubrieron todo su territorio. Durante el período de oro de la minería, las vías indujeron la formación de ciudades actualmente conservados como patrimonio material del Brasil colonial. Con el declive del oro, estas ciudades se convirtieron en el núcleo de una cultura de subsistencia que se dio dentro de los bosques. Esta cultura, llamada Caipira, tiene su origen en el mestizaje portugués e indio y sus características incluyen la siembra de la milpa, las herramientas, las técnicas, las tradiciones, la arquitectura, la organización espacial y, sobre todo, un estrecho vínculo con los elementos naturales de Alto Valle do Paraíba.

Palabras clave: Caipira, Maíz, Ciudades Coloniales, Rural Barrio, Alto Valle do Paraíba.

\section{ABSTRACT}

The natural landscape of the Upper Paraiba Valley in southeastern Brazil is composed of small hills, rivers, streams and a few remaining fragments of Atlantic forest, which once covered all its territory. During the period of gold mining, pathways induced the formation of cities currently preserved as material heritage of the colonial Brazil. With the decline of gold, these cities became the nucleus of a subsistence culture that occurred within the forests. This culture, called Caipira, has its origins in Portuguese and Indian miscegenation and its characteristics include planting the cornfields, tools, techniques, traditions, architecture, spatial organization and above all, a close link with the natural elements of the Upper Paraiba Valley.

Keywords: Caipira, Corn, Colonial Cities, Rural Neighborhood, Upper Paraiba Valley. 


\section{CONCEITO, MÉTODO E CONTEXTO}

A leitura da paisagem cultural, através de suas formas e da cultura local, aparece como enfoque central dessa investigação. A paisagem é analisada como fato visível e resultado material da produção humana ao longo do tempo, o testemunho das relações entre grupos humanos e território, no qual desenvolveram o seu habitat. Neste sentido, o território é observado por suas formas físicas naturais que gradativamente incorporam formas artificiais, e ao final refletem a vontade de uma identidade, resultado de uma cultura e de um modo de vida.

Esta abordagem requer um pensamento sistêmico, uma reflexão sobre os fatos ocorridos ao longo do tempo, uma análise das transformações que atribuem valor e importância à formação dos lugares e qualificam determinadas configurações. Uma reflexão que nos permite reconhecer as qualidades singulares e insubstituíveis do lugar, discernindo aquelas que verdadeiramente constituem o seu patrimônio e sustentam a sua cultura.

Neste sentido, um elemento artificial que produz certa visibilidade sobre a paisagem não pode ser valorado apenas como resultado da ação do homem sobre o território, natural ou construído, mas deve ser pensado pela sua relação indissociável com os elementos naturais e culturais, que são sempre interdependentes. É neste recorte conceitual que paisagem se torna antes de tudo, um lugar carregado de sentido, em afinidade entre o ser do homem e o seu habitat. Assim poderá ser analisada a partir da relação entre todos os componentes ali existentes, em uma extensão espacial e temporal, onde se manifesta o fenômeno da existência.

Esta pesquisa direcionou o olhar para o contexto específico da paisagem do Alto Vale do Paraíba no Sudeste brasileiro, onde as circunstâncias ambientais retardaram o envolvimento da região nas dinâmicas econômicas mais intensas. O recorte espacial diz respeito a um pequeno vale inserido no alto da serra do Mar, onde a cultura do milho deu suporte à sua ocupação e a formação de unidades rurais de subsistência, implantadas em meio a cidades do período colonial.

Busca-se primeiramente reconhecer e compreender a gênese e as heranças históricas de uma paisagem rural típica de São Paulo, selecionando os marcos culturais que perduraram ao longo do tempo e os processos que resultaram a formação de tradições 
e o desenvolvimento das técnicas empregadas na agricultura. A partir disso, definimos hierarquias e separamos valores que atualmente já se encontram fragmentados e dispersos em meio ao acumulo e a sobreposição de outras paisagens culturais.

Outros condicionantes também influenciaram na importância do recorte espacial. A cidade de São Luiz do Paraitinga, localizada no alto vale, é um dos ricos exemplos do patrimônio colonial paulista. A cidade apresenta o maior conjunto de bens tombados do estado de São Paulo, com mais de 450 imóveis reconhecidos e protegidos (IPHAN,2015). A cidade está condicionada por essa paisagem natural do Alto Vale, implantada junto ao rio Paraitinga, inserida num "mar de morros" e rodeada por pequenos povoados e propriedades rurais que ainda permanecem como reduto dessa cultura rural, conhecida como cultura caipira. No início de 2010, por razões ambientais ainda pouco discutidas, mas relacionadas com as fortes intervenções do homem sobre esse território incluindo o desmatamento, construção de represas e a instalação de duas usinas hidrelétricas (Paraibuna e Santa Branca), as chuvas de verão causaram o transbordamento do rio e a inundação do centro histórico da cidade, comprometendo muitas edificações e arruinando mais de 20 imóveis tombados, entre eles a Igreja Matriz, considerado um dos tesouros desse patrimônio colonial.

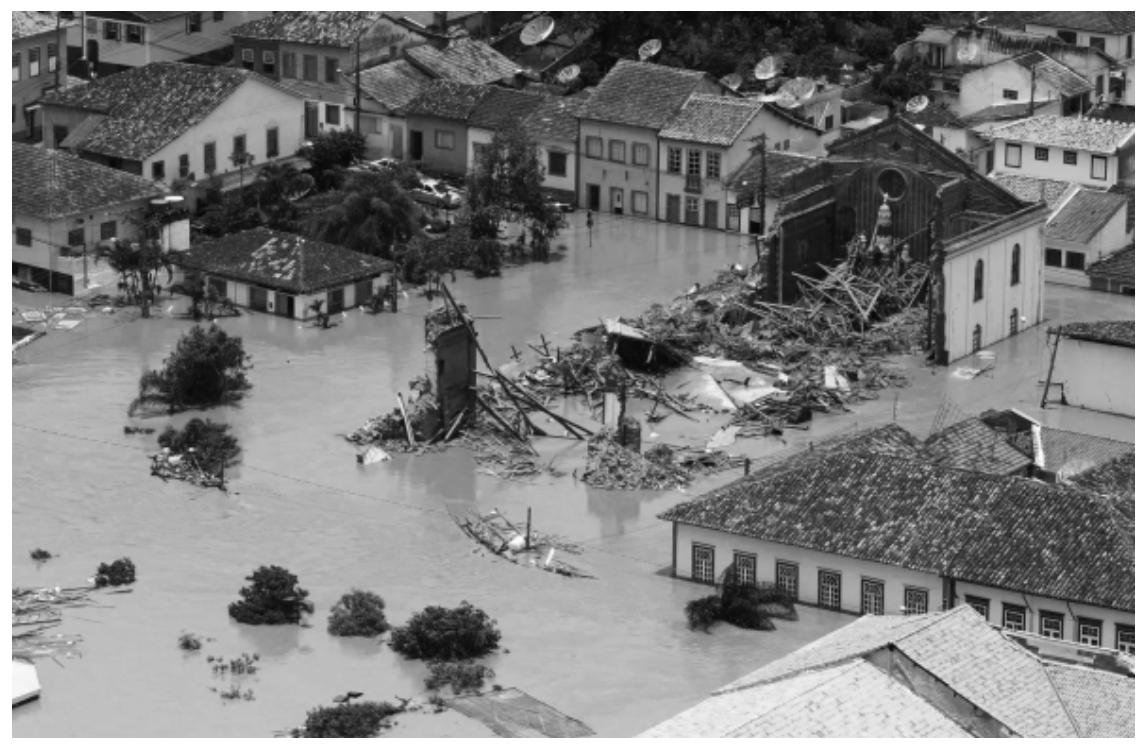

Inundação do centro histórico e destruição Igreja Matriz de São Luiz do Paraitinga em 2010. Fonte: R7 notícias. 
O ano de 2010 ficou marcado pelo intenso trabalho de salvamento do patrimônio histórico. Logo após a inundação, o IPHAN-SP disponibilizou um corpo técnico para auxiliar a população e a prefeitura nos cuidados com os bens tombados, iniciando imediatamente as atividades de restauro e reconstrução do centro histórico da cidade. No ano de 2015 , realizamos pesquisa de campo na cidade e constatamos que, embora nem todos os edifícios estivessem reconstruídos ou restaurados, a comunidade local já havia recuperado seu programa de festas e retornado às atividades cotidianas. Neste contexto é importante destacar que a atuação da população local foi fundamental para a reconstrução dos edifícios e a manutenção da paisagem que em muitos momentos se mostrou simbólica nesse processo. Isso porque, mesmo estando a igreja matriz e outros edifícios tombados na margem do rio e sujeitos às futuras enchentes, os habitantes se recusaram em reconstruílos em outro local, mantendo o lugar como centro das atividades comunitárias.

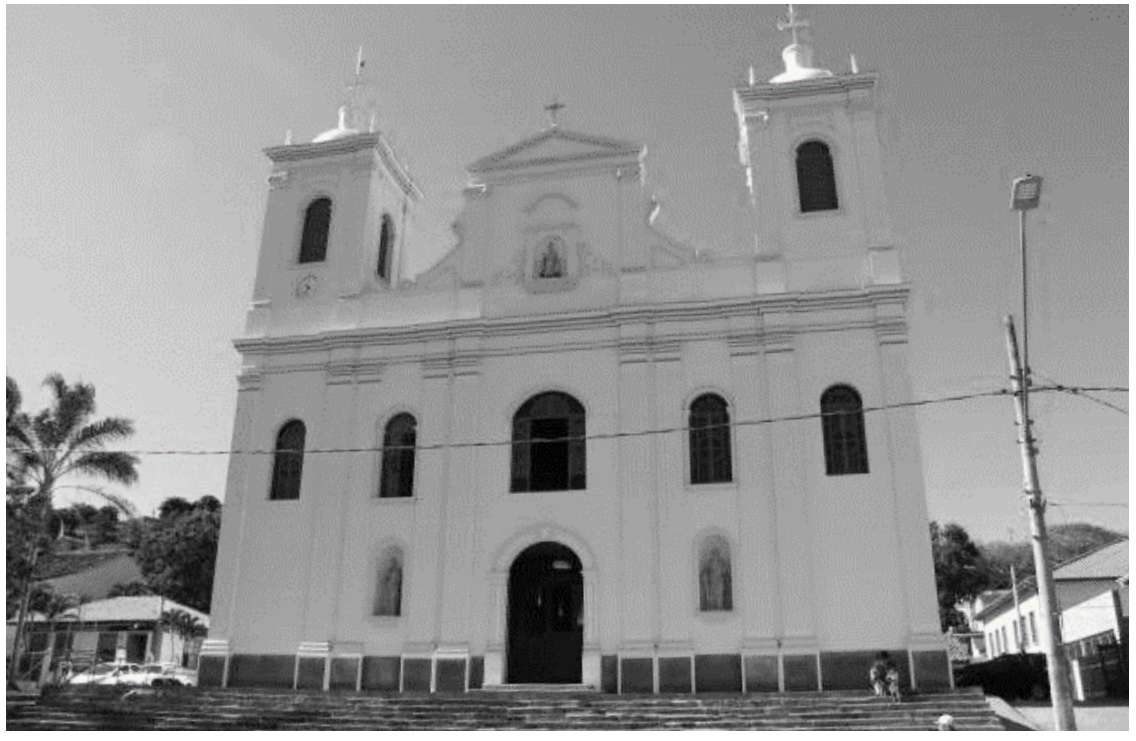




\section{CARACTERÍSTICAS DO TERRITÓRIO DO VALE DO PARAÍBA}

O vale do Paraíba está localizado no território dos estados de São Paulo, Rio de Janeiro e Minas Gerais. A parte paulista se encontra classificada em basicamente duas zonas fisiográficas: alto vale e médio vale superior. Essas duas zonas, embora apresentem recursos naturais distintos - mata, relevo, solo e rios - estão diretamente interligadas por caminhos de terra e água, que nos oferecem um sentido lógico para os processos históricos de ocupação e urbanização do Brasil colonial.

O alto vale é cortado em toda a sua extensão pelo rio Paraitinga, que é afluente do rio Paraíba do Sul. Primeiramente, como podemos observar na imagem 03, o rio Paraitinga nasce no alto da serra da Bocaina, serra contigua à Serra do Mar, e percorre toda a zona do alto vale até desembocar no rio Paraíba do Sul, que por sua vez, percorre as demais zonas fisiográficas do Vale do Paraíba até alcançar o mar na divisa entre os estados do Rio de Janeiro e Espírito Santo. A declividade percorrida pelo rio Paraitinga, que nasce a 1800 metros e desemboca a cerca de 600 metros no rio Paraíba do Sul, proporcionava uma vazão eficiente no território evitando os alagamentos. As interferências do homem sobre o território têm modificado essas dinâmicas naturais como, por exemplo, a implantação da usina hidrelétrica de Paraibuna, que criou uma imensa represa, interrompendo a vazão natural dos rios e a drenagem dos seus sedimentos.

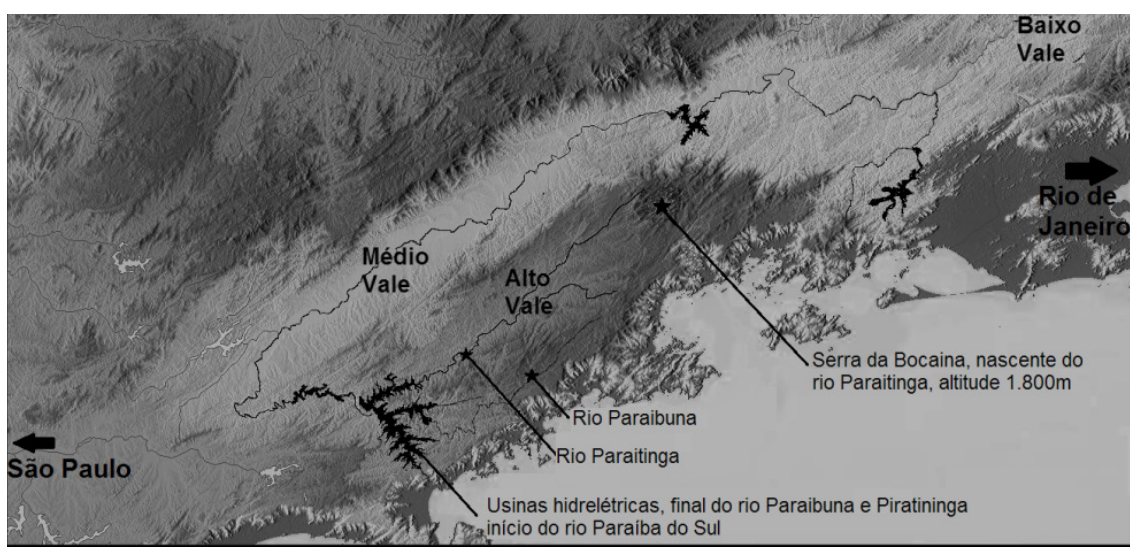

Relevo e localização do alto vale e médio vale superior do rio do Paraíba do Sul. Fonte: Adelita Araujo, 2015, base Maps-For-Free. 
O clima do alto vale é tropical úmido, com temperaturas amenas; onde a altitude é maior, ocorre o aumento da pluviosidade com aumento também da distribuição anual das chuvas. A vegetação de Mata Atlântica foi muito alterada, sendo pouco representativa da sua situação original. Áreas extensas conservadas são raras, o que também limita a dinâmica da rica fauna. O rio Paraitinga, que corta todo o Alto Vale, percorre em meandros encaixados em uma série de morros, dando origem a expressão "mar de morros". Os seus afluentes recortam calotas e planícies arredondadas, que formam pequenas áreas de patamares, às vezes um pouco íngremes.

O médio vale possui uma paisagem distinta do alto vale e tem sua delimitação onde o rio Paraíba recebe as águas do Paraibuna onde, atualmente encontram-se a represa e uma das duas usinas hidrelétricas. Primeiramente, a partir do alto do rio Paraíba do Sul, onde o rio também corre em meandros, o território constitui-se por terraços colinosos até o momento em que o rio faz uma grande curva e muda o seu curso no sentido dos estados do Rio de Janeiro e Espírito Santo. Nesse ponto, o médio vale torna-se uma ampla planície sedimentar que se inicia a $560 \mathrm{~m}$ de altitude. Este trecho mostra-se como uma depressão tectônica que se assemelha a uma grande calha limitada pela serra da Mantiqueira e do Mar. Originalmente esse território era coberto por uma vegetação de mata atlântica, determinada como Floresta Ombrófila Densa, que cobria cerca de $95 \%$ da área e que atualmente se reduziu a cerca de $5 \%$. (DEVIDE, 2013)

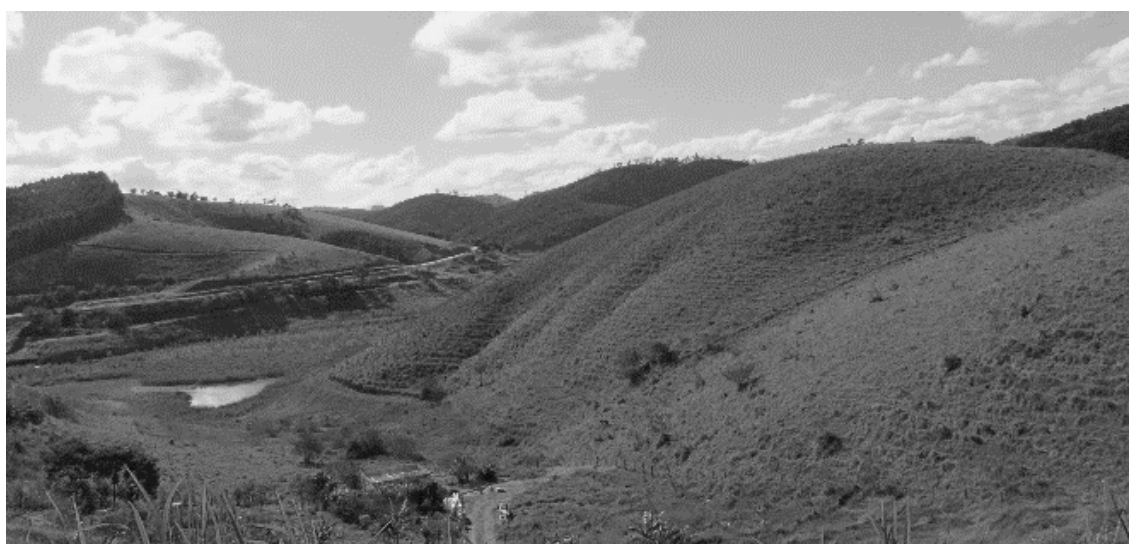




\section{A OCUPAÇÃO DO TERRITÓRIO DO ALTO E MÉDIO VALE}

Segundo relatos de viajantes do período colonial, o vale do Paraíba era uma região ocupada por indígenas e, apesar de prevalecer a presença Tupi, o território era uma rota de passagem para vários grupos, apresentando inclusive lugares com permanência de tribos.

Após a ocupação dos Campos de Piratininga (atual região da cidade de São Paulo), o médio vale foi o primeiro território do interior do Brasil a ser atingido pelos colonizadores europeus. Sua história está associada à presença dos bandeirantes que acessavam a região das minas de ouro partindo de São Paulo, ou ainda quando subiam as serras partindo dos portos de Paraty e Ubatuba. Assim, nos séculos XVII e XVIII, o alto vale e o médio vale superior se tornaram destino e passagem de sertanistas, colonizadores e bandeirantes. Os caminhos que cruzavam os rios deram origem aos pousos que por sua vez se tornaram os núcleos originais de algumas cidades coloniais. No alto vale, Cunha e São Luiz do Paraitinga são as mais representativas deste período.

As cidades do alto vale tornaram-se um patrimônio do período colonial e um testemunho das dinâmicas territoriais promovidas pelo ciclo do ouro. Após o declínio da mineração na região de Minas Gerais e a construção de novos caminhos passando pelo médio vale e ligando as capitais das Províncias, as cidades do alto vale tornaram-se estagnadas, as condições topográficas e climáticas impediram sua inserção no ciclo do cultivo do café e assim, a região permaneceu em áreas de matas ou sendo utilizada por pequenos agricultores que

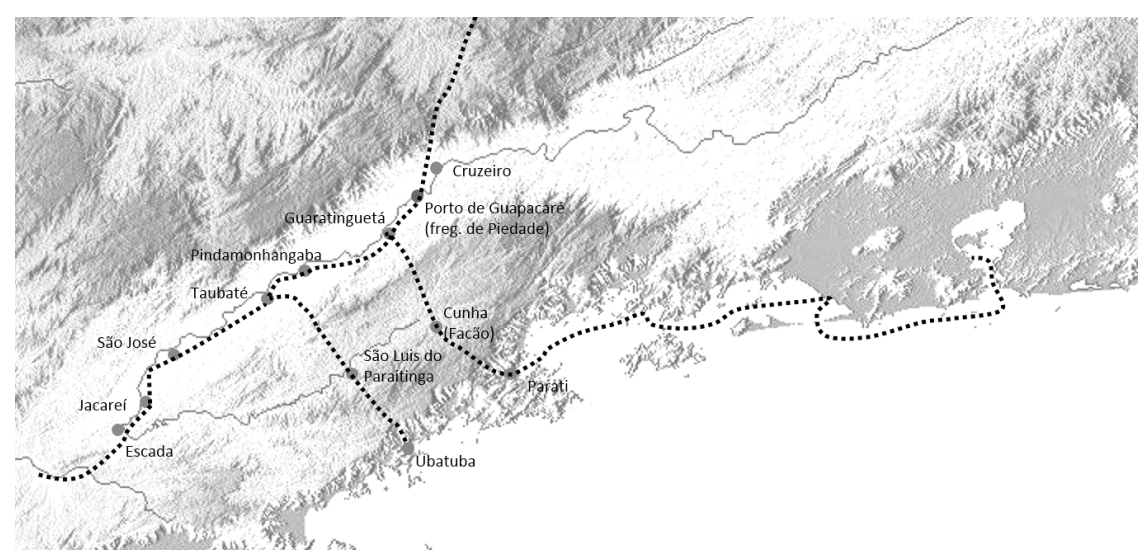
Gerais. Fonte: Jane Victal, 2012, base Map-For-Free. 
cultivavam a terra no sistema de "roças" de subsistência. Esse isolamento, conhecido na historiografia como sertão, favoreceu a formação da cultura material e imaterial muito característica do Alto Vale aqui enfocada.

As cidades de São Luiz do Paraitinga e Cunha, permaneceram como baricentro dessas localidades de subsistência, fornecendo suporte para a vida rural que por mais de dois séculos se manteve relativamente preservada, dando oportunidade ao desenvolvimento da cultura local. Festas, conjuntos arquitetônicos e hábitos cotidianos foram preservados devido ao isolamento que tiveram em relação às regiões mais dinâmicas do estado. Somente no século $X X$ essa paisagem começou a ser transformada, sobretudo pela chegada da pecuária, da extração de lenha e da presença dos carvoeiros.

O médio vale, por sua vez, com um clima mais adequado e uma topografia mais favorecida, concentrou intensos processos de intervenção e ocupação. Desde o início da colonização o rio Paraíba do Sul foi amplamente utilizado em seu trecho navegável com canoas que conectavam as diversas vilas nos períodos colonial e imperial, além de ter posteriormente recebido embarcações a vapor para escoamento da produção.

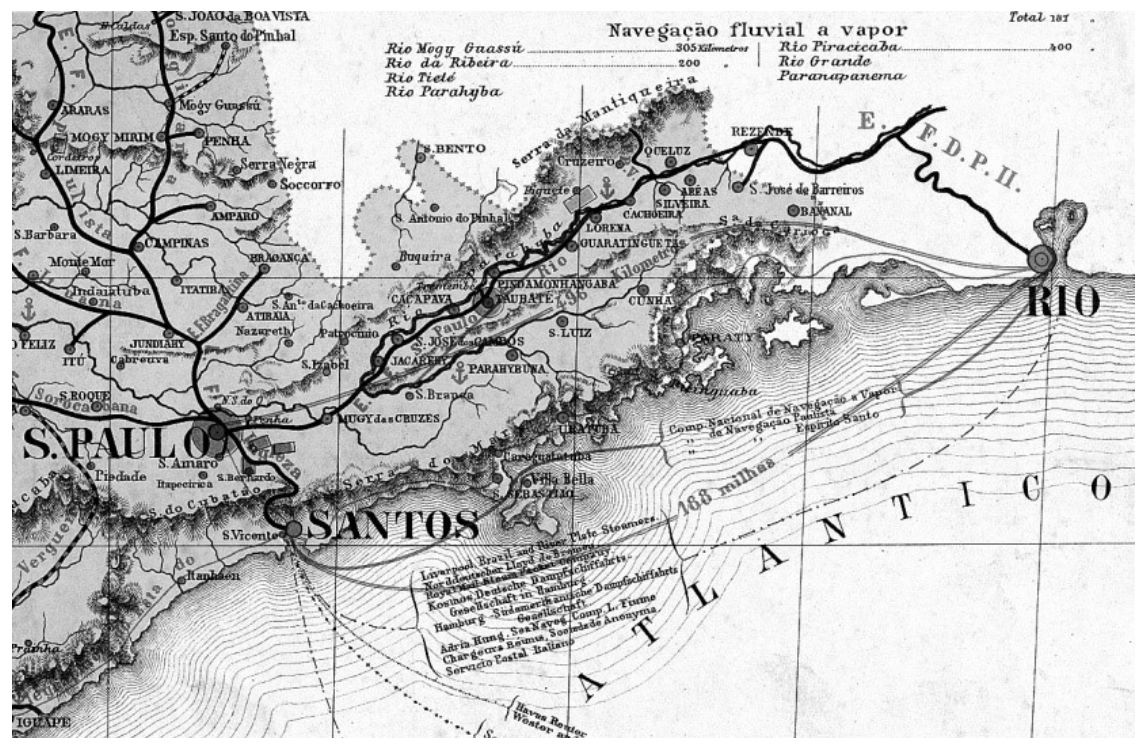

Detalhe do Mapa da Provincia de São Paulo, mandado organizar pela Sociedade Promotora de Imigração de S. Paulo, 1886, mostrando a conexão da linha férrea passando pelo Médio Vale e ligando as cidades de Estado de São Paulo, Memória Publica. 
Um sistema ferroviário também foi construído, ligando as duas capitais, Rio de Janeiro e São Paulo dando impulso ao processo de industrialização. É nesse alinhamento, entre as duas capitais, que se desenvolveram as principais cidades do vale do Paraíba paulista, entre elas Taubaté e São José dos Campos.

É interessante notar, também na imagem 06, a referência à navegação a vapor, no trecho que vai de Santa Branca até as proximidades de Cachoeira, local onde o rio se torna mais acidentado e a navegação é interrompida. $O$ alto vale permaneceu como região isolada do transporte a vapor, sendo atendido pelos chamados "caminhos de terra batida", por carros de bois e tropas de muares.

No início da década de 1940, Carlos Borges Schmidt, quando realizava pesquisas empíricas na região, descreve o alto e o médio vales afirmando que partir de São José dos Campos, e indo em direção à São Luís do Paraitinga, a região encontrava-se dominada por pastos, entremeados por alguns capões e umas poucas lavouras velhas de café. A pecuária de leite aparecia amplamente alternada pelas roças de milho como lavoura dominante. Ao cruzar os ribeirões das Pedras e Capivari, cita a presença de um Cemitério que, segundo a população local, tratava-se de um antigo cemitério indígena. (SCHMIDT, 1944)

Schmidt descreve as condições em que encontrou a região nas seguintes palavras:

Quem penetra no coração da bacia do Paraíba, quer pela estrada que ruma de São José a Paraibuna, quer pela que de Taubaté busca São Luiz do Paraitinga, pode, ininterruptamente, ir observando e aquilatando do grau da marcha, que atingiu e em que prossegue, a transformação, do que resta de vegetação superior, em combustível para consumo industrial e domiciliar. [...] tropas de caminhões carregados de carvão, além de carros de bois transportando lenha. [...] e quando simples caminhos, quase intransitáveis, tropas pejadas de sacarias de carvão. É de se admirar, aqui e acolá, empilhadas na beira do caminho, dúzias às vezes, por outras centenas de sacos, onde os caminhões vêm apanhar. Em alguns lugares, ranchos foram construídos para resguardá-los das chuvas, como na encruzilhada que, no bairro do Paiol, leva o viajante às raias de Natividade. Neste município, carvoeiros e lenhadores ainda não haviam penetrado em 1941." (SCHMIDT, 1944, p. 6-7)

Schmidt registra a passagem de "caminhões após caminhões" transportando carvão que, segundo o autor, corresponde a quarenta metros cúbicos de lenha. "Um simples caminhão 
dá assim vazão, mensalmente, a uma quantidade de lenha que alcança a 2.500 metros cúbicos: uns três alqueires de mato ou seis ou oito de capoeira". (SCHMIDT, 1944, p. 7)

Embora descreva a devastação produzida pelos lenheiros na região do alto vale, Shmidt (1944) relata que encontrou fartamente as roças de milho e feijão aproveitando terrenos propícios que ainda restavam em quantidade. Enquanto o feijão abastecia mercados nas cidades próximas, o milho tinha maior abrangência, sendo utilizado para o consumo local cotidiano, pelas pequenas fábricas de farinha como, por exemplo, a do bairro do Paiol, e para a distribuição no mercado das cidades maiores, como Taubaté.

Na década de 1950, a construção da rodovia Dutra intensificou o fluxo de pessoas e de mercadorias no médio vale, consolidando-o como ligação entre as duas maiores cidades do país, São Paulo e Rio de Janeiro. Essa ligação tem causado um complexo processo de urbanização que tende a formação de uma Megalópole, fenômeno que se caracteriza pela conurbação das mais importantes Regiões Metropolitanas do Brasil.

\section{O CAIPIRA E O MILHO}

Muito conhecido em todo o Brasil por sua culinária, trejeitos, ferramentas de trabalho, modo de falar, vestir e andar, o caipira surge nas capitanias do sul, tendo sua gênese com a miscigenação dos portugueses e índios e pela catequização dos primeiros índios pelos jesuítas. Depois, quando os bandeirantes paulistas começaram a acessar o interior do território, esses hábitos e modo de vida se espalham, recebendo múltiplas feições e características particulares que são únicas em cada região do Brasil.

O milho, alimento tradicional das roças indígenas, aparece como alimento central dessa cultura, que conduziu seu modo de vida na relação de pertencimento ao lugar, cultivando a terra para extrair seu alimento. Com a cristianização dos povos indígenas, surgiu um catolicismo caboclo e com este as festas anuais, sempre permeadas pelas colheitas do milho que forneceu os ingredientes para a culinária caipira.

À época da chegada dos colonizadores europeus, o milho já se encontrava difundido por todo o Novo Mundo - embora nem sempre como alimento principal - e tornou-se um importante aliado dos primeiros bandeirantes nas expedições às regiões auríferas. Roças de apoio eram 
plantadas ao longo dos caminhos, deixando a produção pronta para a viagem de volta. Esses postos de parada acabavam se consolidando em pequenos arraiais onde se estabelecia uma agricultura provisória, restrita ao plantio do milho e complementando a alimentação dos sertanistas, já que contavam também com a caça, a pesca e o mel silvestre nas matas. Antonil (1711), registra um destes postos do sistema de abastecimento itinerante na região do médio vale, referindo-se às roças de Bento Rodrigues nas imediações do Porto de Guaipacaré no Rio Paraíba. Em algumas, o milho era plantado juntamente com a abóbora e feijão, onde também se encontravam criações de animais como porcos e galinhas que eram vendidas aos viajantes. Assim, esses pontos de parada incorporavam outras criações e passavam para o segundo estágio, primeiramente desenvolvendo o comércio e dando suporte às expedições, posteriormente formando arraiais até, mais tarde, se transformarem em pequenos povoados.

Há fartos relatos do início do século XVIII sobre as façanhas de "pessoas antigas", antepassados sertanistas do período do ouro e sobre a marcha dos que seguiam em direção aos sertões. Munidos de espingardas, pólvoras e chumbos, laços, armadilhas, anzóis, arcos e flechas, machados e enxadas, conseguiam todo o alimento que desejavam: carne, peixe, palmito, frutas, mel e até bebidas. Esses, embora vivessem da pesca e da caça, levavam muitas sementes, principalmente de milho, para plantarem quando fosse propício. Retornavam ao lugar da colheita tangidos pela saudade dos alimentos habituais e não pela estrita necessidade de alimento, já que a mata lhes fornecia o necessário para o sustento.

\section{DA ROÇA DE MILHO À MATERIALIZAÇÃO DA CULTURA CAIPIRA NO ALTO VALE}

Durante muito tempo as populações do Vale do Paraíba foram grandes produtores de milho, tornando-se uma das primeiras mercadorias comercializada pelos "caipiras da serra". Os agricultores do alto vale desciam a serra em direção ao litoral com milho e toucinho e voltavam com peixe seco. Esse comércio sofreu altos e baixos chegando a ser extinto devido a uma crise em 1797, quando houve a proibição do fluxo de mercadorias entre o Rio de Janeiro e o Porto de Ubatuba, que se caracterizava quase que na totalidade de aguardente. 


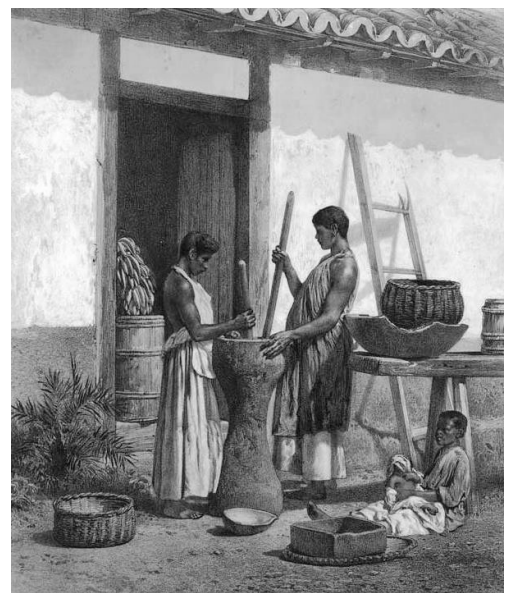

Pilagem de Café, 1861, Litogravura de Jules JosephAugustin Laurens. Fonte: Biblioteca Nacional Digital Brasil.
A farinha de milho desfrutava de grande importância na alimentação do vale do Paraíba. Nas roças e nas cidades, de modo geral, era grande o consumo da farinha de milho, que estava integrada aos hábitos alimentares da população. O milho era também utilizado para a alimentação dos escravos em todo o vale do Paraíba paulista, quer na forma de angu, quer como farinha.

Citados nas crônicas desde a chegada dos colonizadores europeus, nessa paisagem do milho encontramos o pilão, um utensílio muito difundido na cultura caipira cuja origem remonta aos indígenas na América do Sul. Até meados do século XX, era objeto obrigatório em todas as casas do interior paulista. Seu emprego doméstico, além de limpar o milho e produzir a canjica, servia para descascar arroz, limpar café, preparar paçoca, etc.

O pilão foi citado por Hans Staden, viajante ao Brasil no século XVI, quando observou que os Tupinambá do litoral paulista utilizavam uma espécie de gral para socar mandioca, fumo e peixe. Era feito de troncos de madeira escavados, variando conforme o local e o grão que se pretendia socar. Os pilões de madeira possuíam formas e dimensões variadas, com aspectos mais ou menos rústicos. Esse utensílio se proliferou por toda a região, e foi incorporado para o processamento de outras culturas com a do café.

Outro equipamento amplamente utilizado para socar o milho foi o monjolo, desenvolvido a partir da tradição do pilão. Trata-se do desenvolvimento técnico de uma máquina hidráulica destinada ao beneficiamento dos grãos. É formado por uma haste de madeira que suporta de um lado o pau do pilão e de outro um cocho para água, sendo equilibrado ao centro como uma gangorra. Quando o cocho enche de água, ele se abaixa devido ao peso que adquire, enquanto a outra extremidade se levanta; por outro lado, estando na posição inferior o cocho se esvazia e volta a subir, fazendo baixar um soquete pesadamente sobre o pilão que contém os grãos de milho.

Segundo Holanda (1975) os primeiros registros documentais sobre o monjolo hidráulico são do final do século XVIII. O monjolo aparece numa área que se estende desde o norte do Rio Grande do Sul até o centro de Minas Gerais, incluindo algumas localidades de Goiás e Mato Grosso. Movidos por uma roda d'água ou uma pequena bica, podem receber características diferentes em cada região tendo sido uma solução adotada para ampliar a capacidade da pilagem do milho, principalmente para a fabricação da farinha. 
Desenvolvido para facilitar o trabalho da pilagem do grão de milho para confecção da farinha, o monjolo passou a compor a paisagem do alto vale. Em pouco tempo sua finalidade transcendeu para um sentido simbólico e o som de seu funcionamento passou a marcar o ritmo dessa vida rural além de denunciar a proximidade de unidades agrícolas em meio a mata e ao longo dos caminhos.

Em seus relatos de viagem ao Brasil, August de Saint-Hilaire (1779-1853), botânico naturalista francês, logo ao transpor a Serra da Mantiqueira, descreveu suas impressões sobre o monjolo:

A manjola ou monjolo, que também chamam preguiça, foi já descrita por viajantes. [...] Sobre uma peça de madeira vertical e imóvel, é colocada, a maneira duma gangorra, outra peça de madeira, móvel e horizontal; esta última é escavada numa das extremidades como uma larga colher, e na outra, é armada de um soquete bem resistente. A máquina está colocada, como já disse, debaixo de uma pequena queda d'água. O líquido, caindo na espécie de colher que, de um lado termina a viga oscilante, faz inclinar-se esta para o mesmo lado, enquanto a extremidade oposta, armada na parte inferior com o soquete que descrevi, se ergue descrevendo um arco de circunferência; mas enquanto a extremidade escavada se inclina, a água escorre, o peso do pilão sobrepuja o da colher, a máquina range, e o pilão cai pesadamente num cocho destinado a receber o grão. (SAINT-HILAIRE, 1938, p. 106)

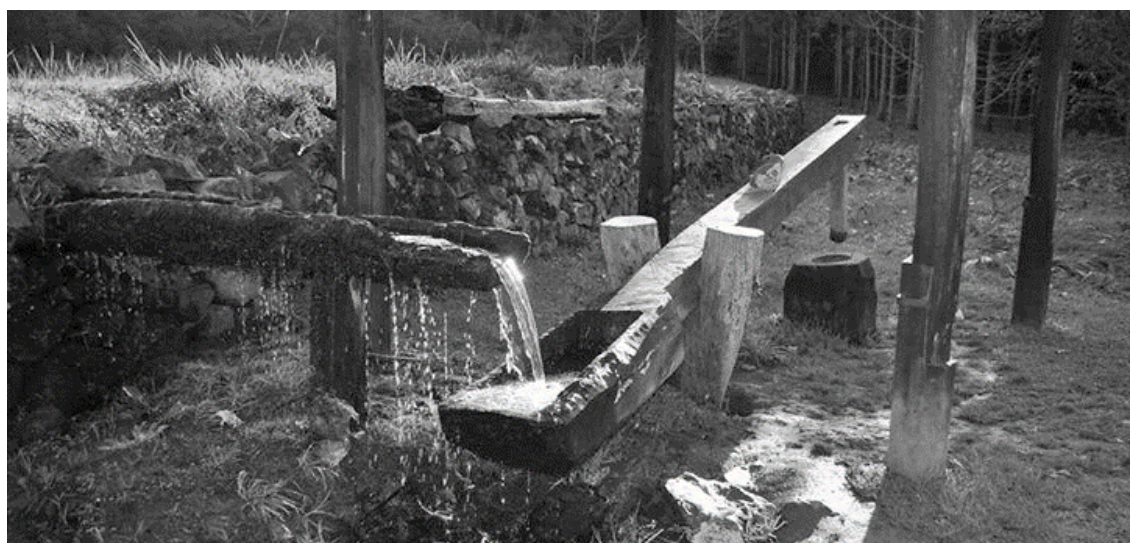


A viabilidade da presença do monjolo está relacionada à uma paisagem característica, com terreno suficientemente acidentado e presença de córrego ou ribeirão, com as habitações construídas no fundo de vale. Assim, a cultura do milho e o tipo humano que o caracteriza, tem a aguada como presença obrigatória para a construção de seu habitat. Representada pela habitação rural, a tradição caipira prescreve a construção das instalações necessárias para manutenção da vida e este habitat vai moldando, ao longo do tempo, as feições que se encontram materializadas na paisagem. Neste contexto, o ruído do monjolo se fez presente, marcando as lidas diárias e sobrepujando, de certa maneira, o som evocado pela fauna do mato e os animais da criação.

Schmidt registra em São Luiz do Paraitinga, por volta de 1947, o depoimento de Benedito Ferreira, um construtor de monjolos e morador do bairro da Fábrica, considerado um dos melhores da região:

Uma meia légua, no caminho de Ubatuba, ao chegar na usina hidrelétrica, toma-se à direita e anda-se mais seis quilômetros. Mais ou menos: é ali. Naquele tempo, o Benedito Ferreira cobrava Cr\$200,00 pela mão-de-obra. A madeira era por conta de quem encomendava. Para haste tinha que ser uma destas: guatambu, urucurana, cangerana, massaranduba. Eram as principais. A peça bruta deveria medir 25 palmos de comprimento (5,50 m), com a circunferência de 15 palmos de comprimento (3,30 m). A peroba não servia - assegurava o Benedito - porque soltava o eixo. Nem madeira leve tampouco, porque perdia o balanço. Para regular o monjolo, depois de pronto, enchia o cocho de água e procurava o balanço, isto é, o ponto de equilíbrio. Aí colocava o eixo. A haste, com o cocho cheio de água, fica de tal forma em equilíbrio, que, a um simples empurrãozinho, apenas com a ponta do dedo, ela se inclina e despeja a água. Foram estas as explicações do Benedito sobre a maneira como regular o monjolo, [...]. E, por fim, prestou esclarecimento a mais. Com uma telha de água (a qualidade suficiente de água corrente para encher uma bica feita com uma telha de canal), um monjolo soca 30 litros de milho, para farinha, em uma hora e meia. [...] (SCHMIDT, 1967, P. 50)

Além do Monjolo, o caipira desenvolveu outros equipamentos para dar suporte às demandas da roça e da vida cotidiana. Construiu sua casa em meio à paisagem natural do Alto Vale, escolhendo áreas entre os morros e os pequenos córregos, desenvolvendo instalações para a manutenção da vida e do "modo de ser caipira", entre elas: currais, chiqueiros, casinhas de despejo, paióis, cocheiras, hortas, roças, monjolo, habitação. 
Pelo sistema de "coivara", técnica herdada dos indígenas e evoluída pelo uso de ferramentas, os roceiros queimavam uma pequena área de mata e passavam a produzir suas roças. Cultivava o milho não apenas para a alimentação dos seus familiares, mas também para criação de porcos e galinhas em substituição a caça e pesca que se tornaram mais eventuais. Além disso, cultivavam o feijão, a mandioca, o fumo e a cana de açúcar para a produção de rapadura e cachaça.

Este tipo de agricultura praticada nas unidades rurais de subsistência, com sua população estabelecida de forma dispersa em todo o território paulista, davam as características desta porção do Brasil, no início do período imperial. Segundo o diário de Saint-Hilaire, sobre a sua viagem do Rio de Janeiro à Minas Gerais, passando pelo Vale do Paraíba, o autor relata:

Todo o talento do lavrador consiste em queimar as matas e semear na época favorável. Pêlo mês de setembro, quer dizer, pelo fim da seca, fazem-se, na terra coberta de cinzas, buracos afastados três a quatro pés, e põe-se em cada um deles alguns grãos de milho. Quando o terreno é de primeira qualidade, e as matas que o cobriram foram queimadas, não brotam ervas, e não se tem maior limpeza a fazer que a de cortar os brotos novos que reaparecem.

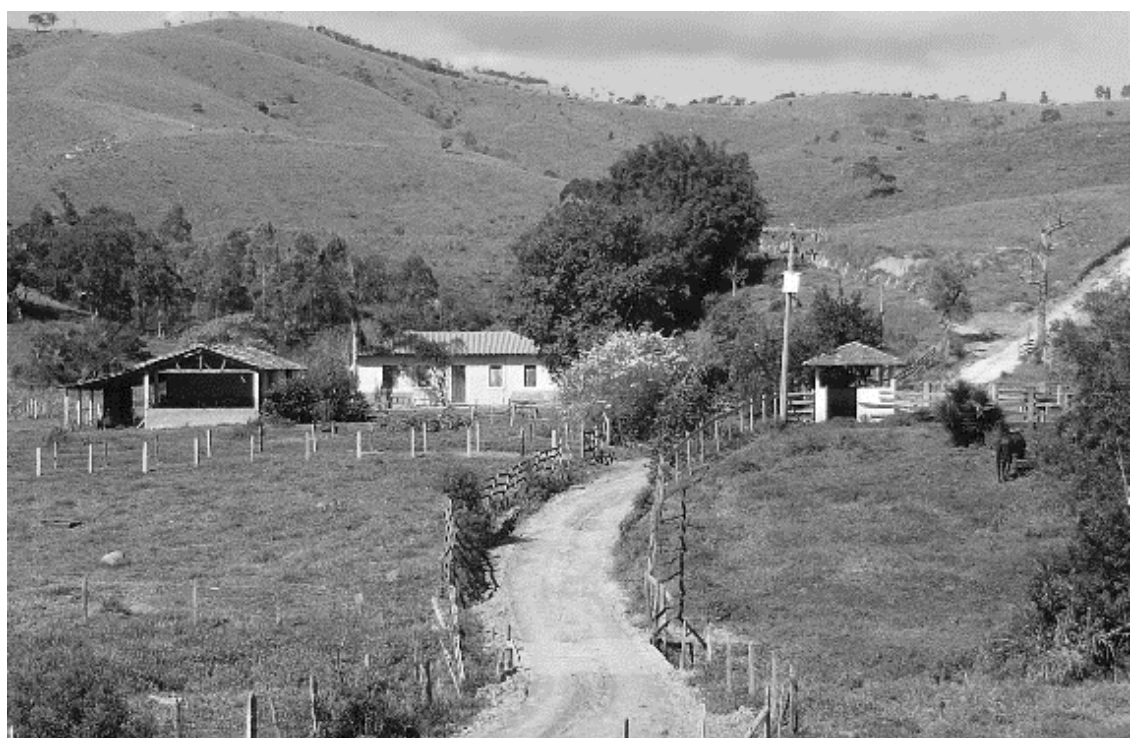

Estrada de chão batido e unidade rural em São Luiz Paraitinga. Fonte: Jane Victal, 2015. 
Mais freqüentemente, porém, não sucede assim, e, um mês após a semeadura, removemse as ervas daninhas com uma espécie de cavadeira ou enxada, sem entretanto escavar a terra em mais de duas e meia e três polegadas (capinar). (HILAIRE, 1938, pag. 120)

O feijão era plantado intercalado ao milho antes de terminar o mês de janeiro, quando limpavam o milharal uma vez mais. Até abril colhiam as duas culturas. O milho colhido em solo pouco fértil dava oitenta vezes a semente plantada, enquanto, em solo fértil e imediatamente após a queimada, chegava à proporção de quatrocentos grãos para cada um plantado. Estando as espigas maduras, eram colhidas e levadas em cestos para o paiol. Quando precisavam do milho, a palha era arrancada e os grãos debulhados com as mãos. Em alguns casos, o terreno recém colhido era mantido para descanso por sete anos, enquanto outro era cultivado. O cultivo pelo caipira caboclo da região acabou constituindo um conjunto de saberes entre eles o conhecimento sobre o ponto da colheita e o manejo do milho que era colhido quando, estando maduro, ainda não estava totalmente seco e assim resistia melhor ao caruncho e sua preservação se dava por mais tempo.

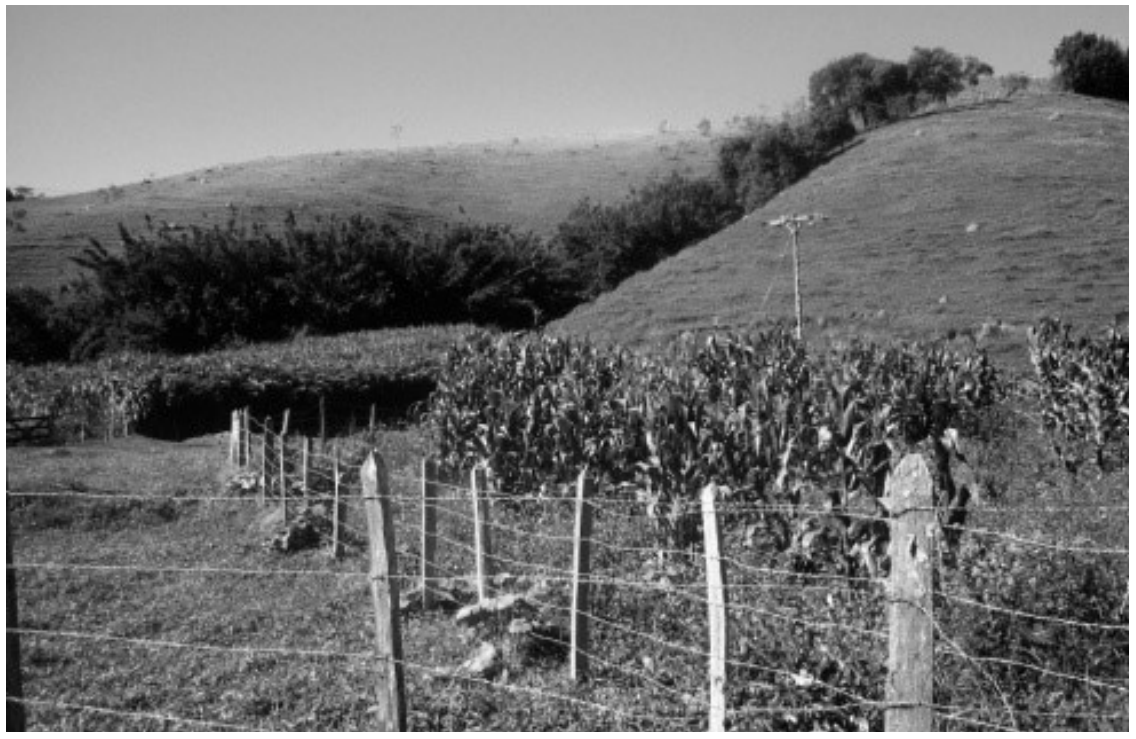



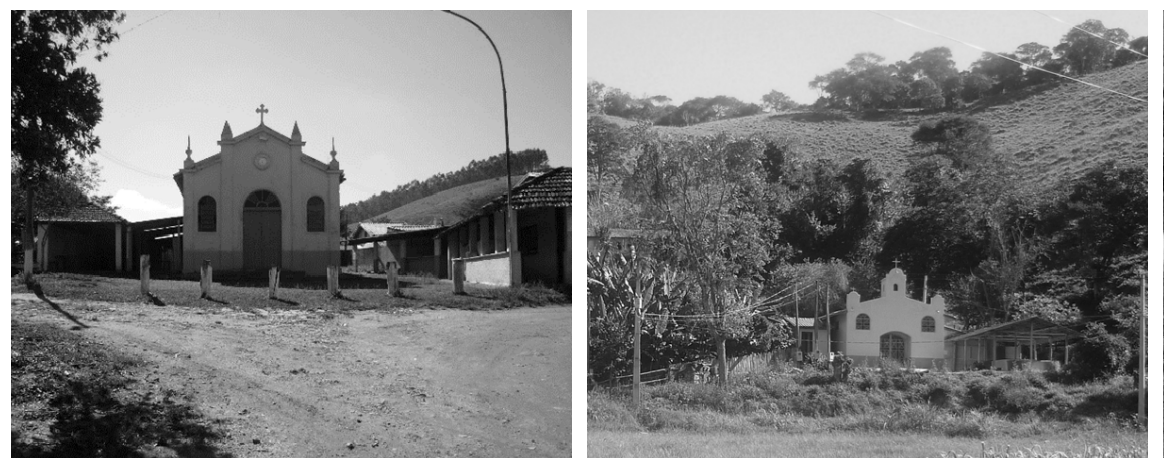

A partir da formação dos pequenos sítios rurais começa a aparecer na paisagem outra configuração espacial, que atualmente conhecemos como "bairro rural". O bairro rural não possuía uma essência necessariamente urbana, ele nasce pela necessidade de uma vida comunitária, de famílias que vivem distantes das cidades, em uma vida puramente de subsistência.

O território do bairro rural fornece as bases para a organização das famílias em um sistema de auxílio mútuo, congregando a vida em comum e pontuando os encontros das missas, os casamentos e nas festas religiosas. Ligadas por caminhos de terra, materializava-se pela construção de uma pequena capela, barracões para festas, paiol de milho e às vezes uma escola e uma pequena venda. O bairro rural tornou-se uma presença constante na paisagem do alto vale, surgindo em meio ao mar de morros que, de tempos em tempos, davam vida a paisagem caipira.

Os conjuntos arquitetônicos dos bairros rurais eram compostos de materiais simples e as capelas apresentavam uma fachada singela, também relacionada com esse modo de vida simples. Algumas vezes, em períodos remotos, surgiam pequenos povoados no entorno das capelas, que ganhavam feições maiores e passavam a nuclear um pequeno conjunto de casas. Essas aglomerações completam os traços característicos dessa paisagem rural, com habitações também singelas que abrigavam as pessoas que, não possuindo terras, trabalhavam nos sítios em parceria mediante o recebimento da quarta ou quinta parte da produção - ou ainda prestando serviços como diaristas.

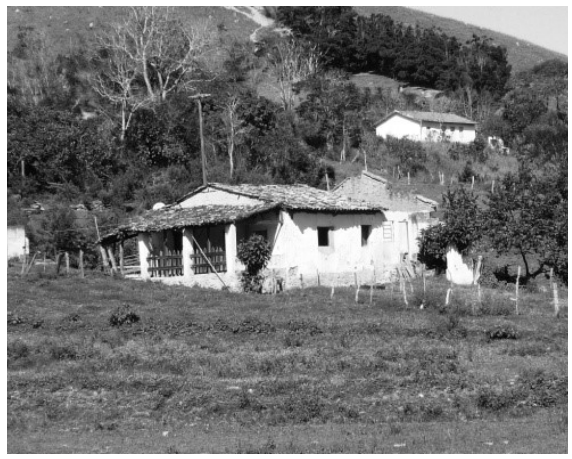

Bairros rurais nas proximidades de São Luiz do Paraitinga. Capela, paiol e barracão de festa. Fonte: Jane Victal, 2015

Habitação rural vernácula no alto vale do Paraíba. Fonte: Jane Victal, 2015. 


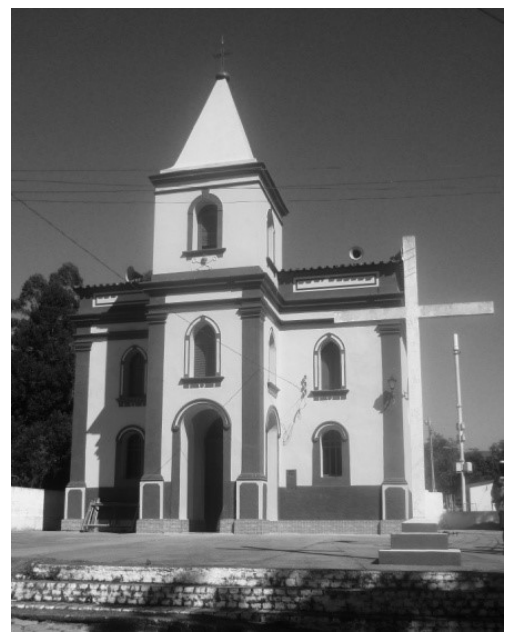

Capela São Pedro, no povoado de Catuçaba, município de São Luiz do Paraitinga. Fonte: Jane Victal, 2015.

\section{A FESTA DO DIVINO ESPÍRITO SANTO NA REGIÃO DO ALTO VALE}

O programa de festas da região do alto vale do Paraíba é bastante amplo tanto em quantidade quanto em variedade e ocorrem durante o ano todo. O setor do turismo soube se apropriar destes eventos locais como valores que são explorados ao máximo, com o apoio das maiores às menores pousadas, que os divulgam para atrair turistas, a maioria proveniente das Regiões Metropolitanas. Essas manifestações são bastante apoiadas pelo poder público que promovem políticas que dão suporte ao turismo, setor que atualmente mais arrecada na região. As prefeituras de São Luiz do Paraitinga e Cunha, os dois municípios mais importantes da rede de cidades em questão - ambas as Estâncias Turísticas - publicam em seus sites uma farta agenda de festas. No entanto, a forma com que as empresas de turismo exploram essas atividades descaracteriza os eventos mais importantes, pois os agentes não estão muito interessados em preservar os valores mais autênticos da tradição, mas atrair consumidores para as atividades de entretenimento.

Merece aqui ser citada a Festa da Cerâmica do município de Cunha quando onde ocorrem eventos dedicados à abertura dos fornos. A cidade conta com uma interessante comunidade de artesãos dedicados à produção da arte da cerâmica que vem ganhando importância, mas sofre a pressão das agências de turismo. No entanto neste artigo merece ser citado com mais destaque a festa do Divino Espírito Santo que tem sua sede no município de São Luiz do Paraitinga.

A festa do Divino tem profundas raízes no período colonial. Os estudos sobre suas raízes e desenvolvimentos no Brasil já contemplam resultados principalmente entre os antropólogos e folcloristas. Sua importância recai devido ao fortalecimento da identidade local, na preservação de traços da oralidade, no seu caráter de memória com padrões coletivos, no seu simbolismo que mantém a coesão social entre outros valores que a compõem.

Em São Luiz do Paraitinga, a festa do Divino mantém alguns parâmetros tradicionais que são perpetuados enquanto renova outros a cada ano. Portanto possui grande plasticidade e potencial para desenvolvimento da criatividade partindo do arcabouço das tradições locais. Não é uma simples somatória de elementos, mas a reelaborarão de eventos singulares que se repetem anualmente. Por isso, possui uma dinâmica onde o grupo social age sobre si mesmo, elaborando e modificando a realidade da comunidade. Na medida em que o 
seu principal elemento é meditar sobre as bênçãos recebidas e retribuir com dádivas buscando com isso garantir as bênçãos para o ano seguinte, possui profundo caráter de transformação social. Além disso, a coleta de alimentos e a distribuição gratuita destes como um dos momentos singulares da festa remonta às suas origens, restituindo princípios e valores sobre a vida em comum do cristianismo primitivo. Isso é reafirmado pelas duas datas importantes em que festa mantém pontos culminantes: a Páscoa e o Pentecostes. As atividades relativas à festa do Divino nessas localidades são dirigidas por comitivas eleitas pela comunidade e ocorrem praticamente durante o ano todo. O seu fechamento é marcado pela indicação dos festeiros (organizadores) para o ano seguinte. Ao iniciar os trabalhos do ano, uma Bandeira dedicada ao Divino é elaborada bem como alegorias que representam fatos importantes da realidade coletiva. Como exemplo, podemos citar exposição em altar da foto da matriz no ano em ocorreu a sua destruição pela inundação de 2010 . Esta bandeira fica depositada no império e é transportada em procissão aos bairros rurais da região pelos festeiros, permanecendo em cada local por um período.

O fato de não ocorrer apenas nos núcleos urbanos, mas a bandeira do Divino "passar" pelos bairros rurais para arrecadar donativos que servirão à festa, traz interesses específicos à nossa pesquisa. Além de ser o elo entre espaço urbano e rural, em sua origem, essa festa se relacionava com a produção agrícola quando os roceiros agradeciam com doações do melhor da colheita ou da criação, buscando garantir a produção do ciclo anual seguinte. Portanto, a festa do Divino está associada às sociedades predominantemente rurais, organizadas em função dos pedidos de boas colheitas. Quando constatamos na atualidade o recolhimento de prendas pelos grupos de folia com ainda mais relevância nas zonas rurais, percebemos que, nessa região, a festa do Divino reforça a crença na ligação direta com a natureza. Neste contexto, mais do que esperar uma benção do clero, ao entregar suas melhores reses ao Divino, as famílias fazem isso baseado na certeza de que obterão retornos com o aumento da fertilidade da terra ou dos seus animais.

Assim, essa festa manifesta-se como a relação entre o espaço urbano e rural, quando são promovidas séries de eventos menores que preparam uma ocasião mais culminante, quando os rituais são realizados na cidade sede, tendo a igreja matriz como ponto focal. Durante os preparativos e na efetivação dessa festa, há disputas e negociações políticas bem como a reafirmação de hierarquias, reforçando ou transformando os papeis sociais e 
espirituais da comunidade. Para isso, ritualiza as relações sociais dando-lhes visibilidade, bem como estabelece valores aos espaços que se tornam simbólicos dessas relações. Abre momentos excepcionais no cotidiano, estimulando o imaginário e resultando em criações alegóricas que dão suporte as narrativas de profundo caráter curativo, estimulando com isso a coesão entre os membros da comunidade. Finalmente, baseia-se no estímulo à gratidão e à dádiva, comportamentos que assumem destaque entre os processos que a contém.

Há uma grande quantidade de objetos estéticos que se relacionam à festa do Divino, que a adornam e representam, tornando-as exuberantes eventos cenográficos: coroas, cetros e bandeiras, impérios, andores, indumentárias, tapetes, instrumentos musicais, oferendas, etc. também contempla ricas encenações teatrais, estimula as produções musicais e literárias vernáculas e místicas, estabelecendo um retorno experiencial e mnemônico às raízes culturais da comunidade local.

Embora apenas de forma introdutória neste artigo, devido à importância que assume nas nossas investigações, vale citar outro aspecto relativo ao meio rural. Trata-se de algo que é possível constatar por meio da observação empírica dos conjuntos arquitetônicos remanescentes nos bairros rurais. Em quase todas as capelas investigadas observamos também o barracão de festas além de outras instalações menores que denunciam a presença de eventos comunitários bastante regulares e uma vívida cultura camponesa na região. Acreditando muito mais nesses pequenos eventos como fatores agregadores e de reprodução da cultura local - em oposição aos grandes eventos incorporados e promovidos pelas empresas do turismo - o que nos leva a dedicar cuidadosa atenção aos estudos dessa realidade mais singela da vida caipira.

A Festa do Divino constitui-se como um evento que está associado a toda essa conjuntura do espaço do alto vale - a cidade colonial, o bairro rural, a casa na roça e o próprio caipira - mostra-se como um testemunho da história do lugar, de suas formas físicas de seus significados, proporcionando ao lugar o que SABATÉ (2004) chama de "llocs comunicatius" - lugares comunicativos ou lugares que comunicam. 


\section{A AMEAÇA AO PATRIMONIO E A CULTURA CAIPIRA}

Contudo, há décadas observamos focos de degradação da paisagem do alto vale. Ab'saber (1958), ao descrever a região em meados do século XX, já alertava para o problema e sinalizava para a extinção e declínio da cultura caipira:

Bairros rurais e arraiais, gravitando econômica e socialmente em torno dos raros centros urbanos de certo relevo na região, têm sido a base comunitária da vida de uma população de lavradores de baixo padrão técnico-cultural e atividades econômicas rudimentares. Por esse motivo não têm podido resistir à transformação, muitas vezes violenta, que vem atingindo a zona rural da região, pois se pode encontrar aqui, ainda em processo, a expansão da pecuária de leite igualmente provocada pelos mineiros. As queixas frequentes, as questões judiciais numerosas, exprimem a má vontade e a resistência que os velhos habitantes tentam, inutilmente, opor ao alastramento dos pastos. (AB'SABER, 1958, p. 177)

Na imagem podemos observar a degradação da cidade de Redenção da Serra, que teve formação devido aos processos rurais de subsistência e que devido ao alagamento da represa Paraibuna teve parte de seu patrimônio destruído.

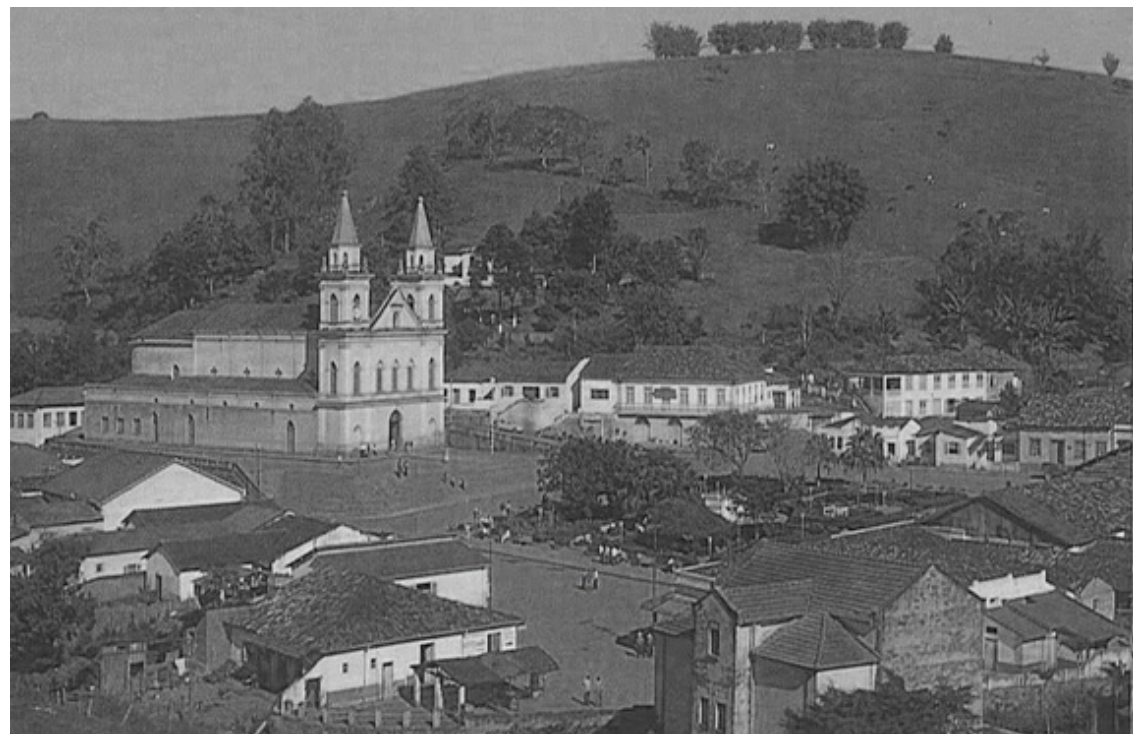

Imagem antiga da cidade de Redenção da Serra e situação atual da cidade. Fonte: http://www. redencaodaserra.sp.gov.br/ e Jane Victal, 2015 


\section{CONCLUSÃO:}

Após alguns anos de pesquisa sobre o Vale do Paraíba, principalmente de sua parte paulista, nos deparamos com a condição muito singular deste território. O caráter multidisciplinar da pesquisa nos coloca desafios e a necessidade de aprofundar algumas temáticas pouco tradicionais na área do patrimônio. Também é preciso quantificar, catalogar e classificar com exatidão os elementos que compõem essa paisagem cultural, bem como analisar de forma mais precisa as ameaças que atualmente estão apenas pontuadas. Cidades históricas, bairros rurais, sítios de roça, usos cotidianos de utensílios e todos os eventos próprios dessa paisagem cultural estão ainda presentes, mas sofrem a pressão da urbanização e dos modos de produção de riquezas do capitalismo global.

O que se faz urgente e imprescindível neste momento é estabelecer um debate sobre a importância da preservação de traços e modos de vida na escala regional, definindo parâmetros para conduzir as transformações de forma menos abrupta, com o objetivo de evitar ou minorar a eminente extinção dessa paisagem cultural. Acreditamos que essa preservação depende tanto de uma visão sistêmica sobre a cultura quanto da participação das universidades, agentes públicos e principalmente da comunidade local, que devem focar-se nas práticas cotidianas que moldam o significado dos lugares.

O abandono das tradições, na busca de adequação às condições atuais de sobrevivência, promove a desintegração dos laços entre território e o patrimônio material e imaterial, incluindo aqueles que mantêm vivos os cenários autênticos das cidades históricas do período colonial. A ausência dos suportes visíveis da memória coletiva intensifica a perda das relações da comunidade com o seu patrimônio que, na medida em que deixam de ser utilizados e referenciados, perdem importância no contexto cotidiano, levando rapidamente a sua degradação pela falta de cuidado e atenção da população local.

Conclui-se que a degradação da paisagem cultural do Alto Vale está ligada aos processos predatórios de modificação do território, impedindo que a cultura caipira continue se reproduzindo. O primeiro deles ocorreu com a extração desmedida da madeira pelos lenheiros que deixaram o solo sem nenhuma cobertura vegetal. Soma-se a isso o abandono da técnica da coivara que, atualmente é combatida no Brasil devido ao entendimento equivocado sobre o seu uso. O seu abandono está associado as ideias progressistas de 


\section{ID_PESQUISAS}

desenvolvimento tecnológico desvinculadas do pensamento crítico. Enquanto um olhar precipitado atribui o desmatamento à coivara, esta foi utilizada como técnica milenar pelos indígenas dentro de moldes tradicionais que acompanhava o ritmo natural de regeneração da mata atlântica e poderia ser retomada como prática em favor de uma agricultura de abastecimento local bastante produtiva, dispensando o plantio de grandes áreas e o uso de agrotóxicos.

Em um processo complexo que envolve muitas dinâmicas, a cultura do caipira passou a ser substituída por outras culturas que desequilibram as condições do meio ambiente do Alto Vale, como é o caso, por exemplo, da pecuária extensiva e da indústria de laticínios. Os pecuaristas, vendo o solo aberto e sem nenhuma cobertura vegetal, passam a criar o gado em extensos pastos, sem a preocupação com a recuperação da Mata Atlântica. Por sua vez, o gado pisoteia os pequenos morros do vale impedindo a permeabilidade do solo e ocasionando uma absorção inadequada das águas das chuvas, que passam a correr diretamente para os pequenos córregos e rios, aumentando o volume de água. Tudo isto, combinado à construção de represas para o abastecimento de água das grandes regiões metropolitanas e a instalação de usinas hidrelétricas, promovem assoreamentos, enchentes e desmoronamentos de terras como os que observamos em 2010, no município de São Luiz do Paraitinga.

Por isso, afirmamos que o reconhecimento da paisagem cultural cumpre um papel fundamental se o objetivo for equilibrar desenvolvimento local com preservação nessas regiões de interesse público onde ainda é possível encontrar, mesmo de forma tênue, um tipo de patrimônio que congrega paisagem, lugar e cultura de forma autêntica. 


\section{REFERÊNCIAS BIBLIOGRÁFICAS}

AB'SABER, A. N.; BERNARDES, N. (1958). "Vale do Paraíba, Serra da Mantiqueira e arredores de São Paulo". Rio de Janeiro: Conselho Nacional de Geografia.

ANTONIL, A. J. (1711). "Cultura e Opulência do Brasil por suas Drogas e Minas". Lisboa: na Officina Real Deslandesiana.

BIBLIOTECA NACIONAL DIGITAL BRASIL. Acesso em: 15 julho de 2015. Disponível em <http://acervo. bndigital.bn.br/sophia/index.html>

CARTE GÉNÉRALE DE L'ÉTAT DE SÃO PAULO. (1910) Avec indications sur l'Agriculture, Le Commerce, l'Instruction Publique, l'Industrie et la Colonisation. Dresséo par la Commission Géographique et Géologique de São Paulo, Ingénieur em Chef, João Pedro Cardoso, Echelle 1/2.000.000.

DEVIDE, A. C. P. (2014). "História ambiental do vale do Paraíba". Tese de doutorado - Universidade Federal Rural do Rio de Janeiro.

HOLANDA, S. B. de (1975). "Caminhos e Fronteiras". Rio de janeiro: Livraria José Olympio Editora.

IPHAN, Instituto do Patrimônio Histórico do Brasil. Acesso em 09/08/2015. Disponível em: <http://portal. iphan.gov.br/pagina/detalhes/388/>

MAPPADAPROVINCIA DE SÃO PAULO. (1886). Organizado pela Sociedade Promotora de Immingração de S. Paulo.

SABATÉ, J. (2004). "Algunes lliçons dels llocs amb esdeveniments associats". In: Llocs Amb Esdeveniments - Event Places, Congrafic S.A, Barcelona.

SAINT-HILAIRE, A. de (1938). "Viagens pelas províncias do Rio de Janeiro e de Minas Gerais". 2 vols., companhia Editora Nacional, São Paulo.

SCHMIDT, C. B. (1944). "Paisagens Rurais. O Paraíba e o Paraitinga - A Paranapiacaba”. São Paulo: Secretaria da Agricultura, Indústria e Comércio, diretoria de Publicidade Agrícola.

SCHMIDT, C. B. (1967). "O Milho e o Monjolo. Aspectos da Civilização do Milho. Técnicas, Utensílios e Maquinaria tradicionais". Documento da Vida rural № 20. Rio de janeiro: Ministério da Agricultura, Serviço de Informação Agrícola.

STADEN, H. (1999). "Primeiros registros escritos e ilustrados sobre o Brasil e seus habitantes". Tradução de Angel Bojadsen, São Paulo: Editora Terceiro Nome. 